\title{
Cistite glandular evoluindo com uropatia obstrutiva
}

\author{
Cystitis glandularis evolving with obstructive uropathy
}

\section{Autores}

Humberto Elias

Lopes $^{1}$

Carlos Eduardo

Dainezzi Bolognani²

Fabiane Corbelli

Roberti ${ }^{3}$

Leonardo Cunha

Dentz ${ }^{4}$

Fernando Emílio

Quinteiros Recaverren ${ }^{5}$

'Serviço de Urologia -

Departamento de Cirurgia

- Universidade Federal

de Juiz de Fora - Juiz de

Fora, MG, Brasil

${ }^{2}$ Faculdade de Medicina/ Universidade Federal de Juiz de Fora - Juiz de

Fora, MG, Brasil

${ }^{3}$ Faculdade de Medicina/ Universidade Federal de Juiz de Fora - Juiz de

Fora, MG, Brasil

${ }^{4}$ Serviço de Anatomia $\mathrm{Pa}$ tológica- Hospital Monte

Sinai de Juiz de Fora -

Juiz de Fora, MG, Brasil

${ }^{5}$ Serviço de Urologia -

Departamento de Cirurgia

- Universidade Federal

de Juiz de Fora - Juiz de

Fora, MG, Brasil

Data de submissão:17/06/2009

Data de aprovação: 13/08/2009

Correspondência para: Humberto Elias Lopes

Rua Padre Vieira, 11

Bairro São Mateus - Juiz

de Fora - MG

CEP: 36025-070

E-mail: lopesh@terra.com.br

Tel: (32) 9987-8584 /

(32) 3216-4553

Declaramos a inexistência de conflitos de interesse.

\section{Resumo}

Introdução: Cistite glandular é um processo proliferativo benigno e infrequente da mucosa vesical, caracterizado por proliferação do epitélio e, em alguns casos, formação de glândulas intestinais. Alterações metaplásicas na cistite glandular são bem documentadas na literatura, embora sua etiologia não seja totalmente esclarecida. Relato do caso: Relatamos um caso de cistite glandular em um paciente de 55 anos, apresentando sintomas miccionais irritativos e obstrutivos persistentes sem resposta à terapia com alfabloqueadores. Ultrassonografia evidenciou lesão vegetante no trígono vesical e o paciente foi submetido à ressecção endoscópica por duas vezes e evoluiu com ureterohidronefrose bilateral. Dado o extenso acometimento vesical e a persistência dos sintomas, o paciente foi submetido a cistoprostatectomia e neobexiga ileal com boa evolução pós-operatória. Discussão: Há duas formas de cistite glandular: típica e intestinal. A forma típica é a mais comum e a intestinal é marcada pela produção de mucina, mais frequentemente associada ao adenocarcinoma de bexiga. A maioria dos casos de cistite glandular é assintomática, sendo que os pacientes sintomáticos normalmente apresentam hematúria, sintomas urinários irritativos e típicos de cistite crônica. Há controvérsias sobre o tratamento precoce agressivo, sendo que vários estudos propõem a ressecção transuretral e o acompanhamento com biópsias.

Palavras-chave: bexiga, cistite glandular, obstrução urinária.

[J Bras Nefrol 2009;31(4):307-310]@Elsevier Editora Ltda.

\section{Abstract}

Introduction: Cystitis glandularis is a rare, benign, proliferative process of the mucosa of the urinary bladder characterized by epithelial proliferation and occasional formation of intestinal glands. Although its etiology is unknown, cystitis glandularis has been associated with chronic stimulation of the mucosa of the urinary bladder due to urinary tract infection, obstruction, and indwelling catheters, which may lead to overproductive changes in mucosal cells and glandular metaplasia of transitional epithelial cells. Case report: A 55-year-old man was admitted to our hospital with urinary symptoms that did not respond to alpha-blockers. On ultrasound, a vegetating lesion in the vesical trigone was observed. After two unsuccessful endoscopic resections of the lesion, the patient developed bilateral ureterohydronephrosis. Considering the extension of the lesion and the persistence of urinary symptoms, cystoprostatectomy with an ileal neobladder reconstruction was performed. The histopathological examination confirmed cystitis glandularis. Discussion: There are two forms of cystitis glandularis: intestinal and typical. The latter is more frequent, while the intestinal is associated with mucin production and adenocarcinoma of the bladder. Clinically, cystitis glandularis manifests with hematuria and irritative and obstructive urinary complains typical of chronic cystitis. However, most cases of cystitis glandularis are asymptomatic. In the present report, invasive treatment was mandatory, due to failure in transurethral resection and to development of hydronephrosis.

Keywords: urinary bladder, cystitis glandularis, urinary obstruction. 


\section{INTRODUÇÃO}

Cistite glandular é um processo proliferativo benigno e infrequente da mucosa vesical, caracterizado histologicamente por aglomerados submucosos de células transicionais que sofreram metaplasia glandular. Normalmente, é um achado microscópico e muito raramente são diagnosticadas lesões macroscópicas. ${ }^{2,3}$

Geralmente, o diagnóstico é realizado acidentalmente ${ }^{1,3}$ ou durante a investigação de sintomas irritativos ou de hematúria. ${ }^{1}$ A etiologia da cistite ainda não está bem estabelecida. Acredita-se que ela seja causada pela inflamação crônica da lâmina própria, possivelmente resultado da exposição prolongada a agentes irritativos. ${ }^{4}$

A cistite glandular acomete geralmente homens na faixa etária da quinta década, de forma assintomática, mas quando se manifesta como lesões inflamatórias prolongadas, às vezes pseudotumores, causa sintomas miccionais irritativos ou hematúria. ${ }^{4}$

Relatamos o caso de um paciente que apresentava sintomas urinários obstrutivos e irritativos, em virtude da presença de cistite glandular do tipo intestinal, flori$\mathrm{da}$, acometendo extensamente o trígono vesical e ocasionando uretero-hidronefrose bilateral. Ele foi submetido a tratamento cirúrgico radical e derivação urinária.

\section{Relato do Caso}

Paciente de 55 anos, masculino, branco, natural de Volta Grande, MG, Brasil, apresentava sintomas miccionais irritativos e obstrutivos persistentes, a despeito da terapia com alfabloqueadores. Não apresentava hematúria nem infecção urinária. Ao exame digital retal, a próstata não era bem delimitada e sugeria espessamento vesical. Exames laboratoriais não apresentaram alterações (PSA: 2,26 ng/mL e creatinina: $1,0 \mathrm{mg} / \mathrm{dL}$ ). Ultrassonografia revelava rins normais e bexiga espessada, com presença de lesão vegetante em região de trígono vesical (Figura 1), além de volume prostático estimado de $38 \mathrm{~g}$.

Paciente foi submetido à ressecção transuretral, tendo sido ressecada parte da lesão vegetante que apresentava aspecto bolhoso (edema acentuado), limites imprecisos, não identificando os meatos ureterais. $\mathrm{O}$ exame anatomopatológico sugeria cistite glandular. Após 1 mês, o paciente foi submetido à nova ressecção endoscópica, mais extensa, e foi encontrada uma lesão bolhosa, envolvendo toda a base vesical, e o exame anatomopatológico confirmou cistite glandular (Figura 2). Com a persistência dos sintomas obstrutivos, foi realizada uma urografia excretora, tendo sido evidenciada presença de uretero-hidronefrose à esquerda e retardo funcional do rim direito (Figura 3).
A tomografia computadorizada de abdome evidenciou uretero-hidronefrose bilateral, mais intensa à esquerda, sugerindo obstrução ureteral bilateralmente (Figura 4) por acometimento da parede vesical pela doença. Esta evoluiu com elevação de escórias nitrogenadas e, devido ao extenso acometimento da bexiga, optou-se pela realização de cistoprostatectomia e neobexiga ileal (Técnica de Studer), com boa evolução pós-operatória. O paciente, em 2 anos de seguimento, encontra-se continente e a ultrassonografia revela trato urinário superior sem alterações.

Figura 1. USG evidenciando lesão vegetante em trígono vesical.

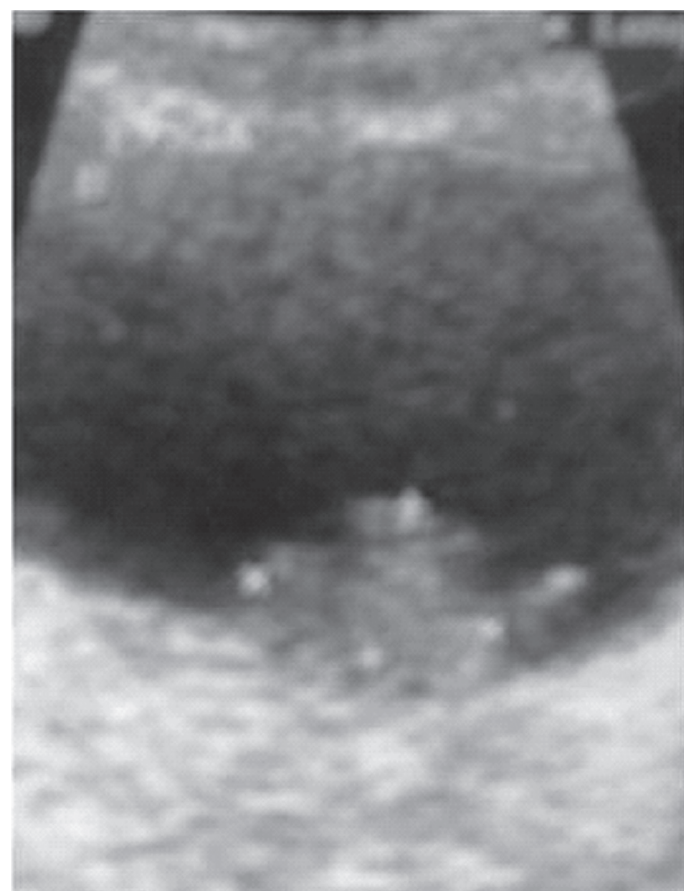

Figura 2. Cistite glandular florida evidenciando epitélio glandular característico.

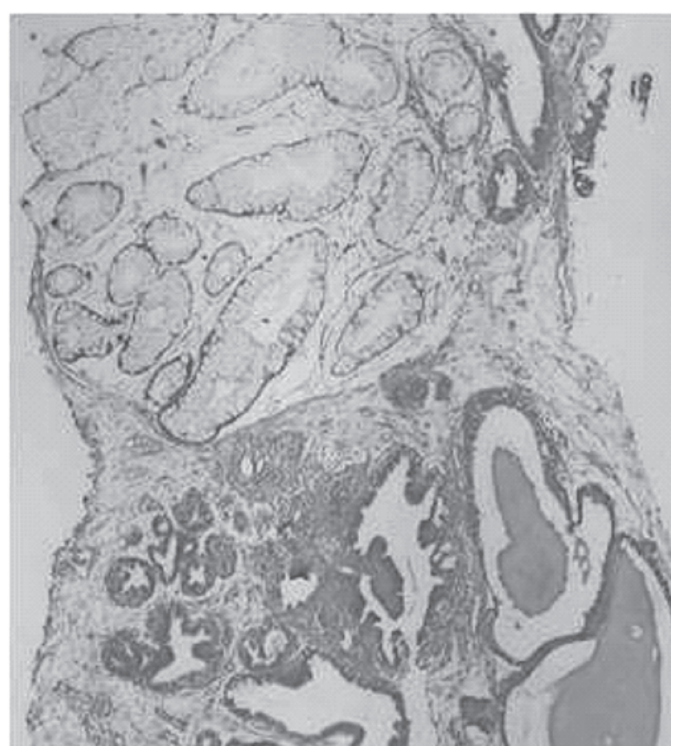


Figura 3. Urografia excretora mostrando ureterohidronefrose à esquerda.

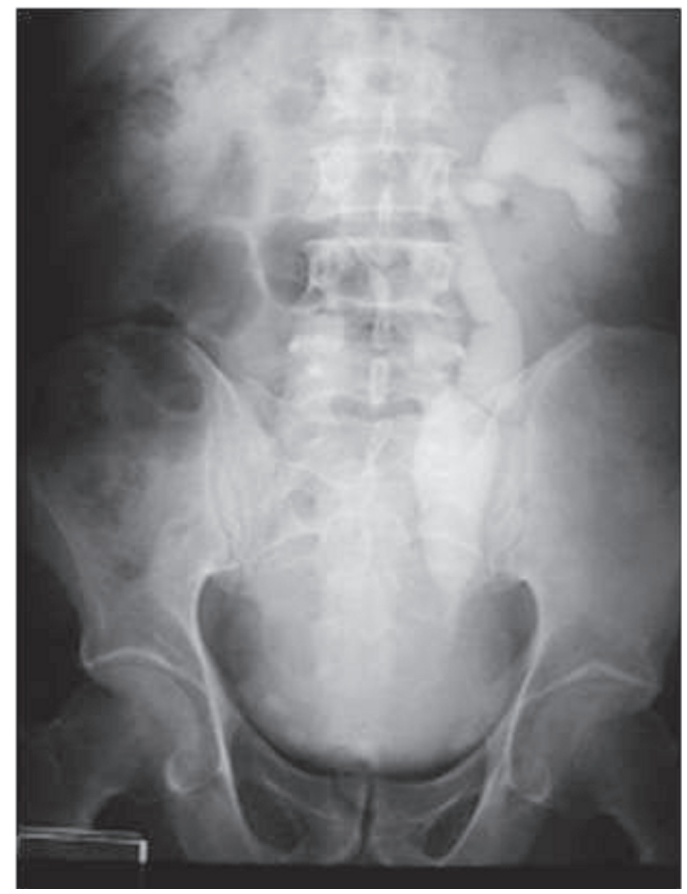

Figura 4. Tomografia computadorizada mostrando uretero-hidronefrose bilateral.

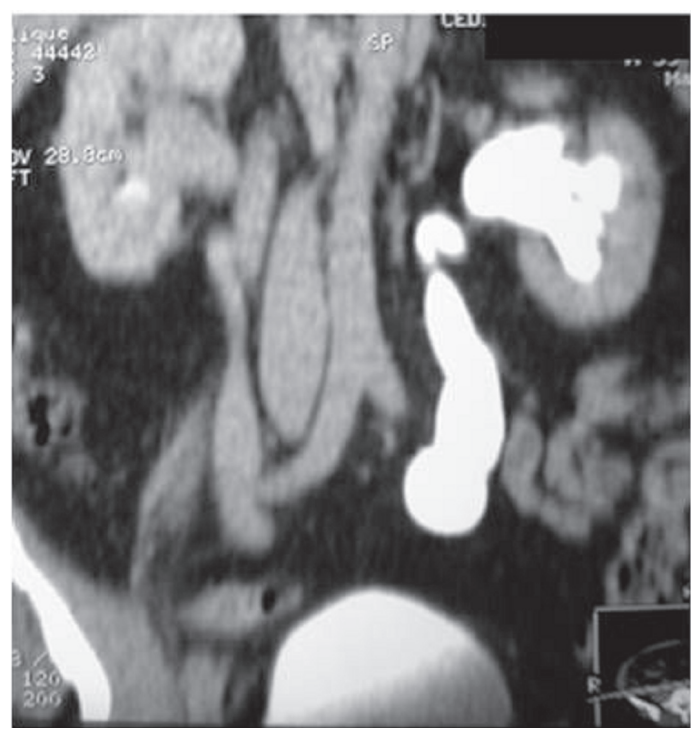

\section{DIscussão}

Há duas formas de cistite glandular: típica e intestinal. A forma típica é a mais comum e consiste na presença de glândulas na lâmina própria revestidas por células em forma cuboide a colunar, circundadas por uma ou mais camadas de células uroteliais. O tipo intestinal é marcado por epitélio colunar e células esféricas moldadas com proeminente produção de mucina, assemelhando-se ao epitélio colônico.
Embora a cistite glandular seja quase sempre um achado microscópico, ela é, por ocasião, visível macroscopicamente, como projeções mamilares irregulares ou nódulos. O tipo intestinal se manifesta por meio de exuberante proliferação associada a edema proeminente e inflamação, podendo resultar em úlceras ou lesões polipoides, suspeitas de malignidade. ${ }^{3}$ A inflamação crônica da lâmina própria causa proliferação do epitélio, resultando em invaginação com formação de aglomerados, criptas e, em alguns casos, glândulas intestinais. Esse tipo de cistite glandular pode ser precedido por ou associado a outras lesões não neoplásicas proliferativas, como aglomerados de Von Brumn e cistite cística, folicular ou polipoide. ${ }^{4}$

Não há relação de cistite glandular típica com adenocarcinoma. ${ }^{2,3}$ Entretanto, o tipo intestinal é questionável quanto à evolução para adenocarcinoma de bexiga. ${ }^{2-5}$ De acordo com Bullock et al., a transformação para adenocarcinoma é rara e ocorre nos casos de fatores predisponentes (litíase vesical, infecção urinária, obstrução infravesical, radioterapia), ${ }^{6}$ sendo recomendado o acompanhamento de todos os pacientes. ${ }^{7}$

A metaplasia intestinal é uma lesão que ocorre na cistite glandular do tipo intestinal e pode ser confundida com neoplasia se a lesão for extensa e difusa, sendo necessário o estudo anatomopatológico para exclusão de malignidade. A história natural da metaplasia e seu comportamento a longo prazo são desconhecidos. ${ }^{5}$ Alguns autores consideram-na uma lesão reativa a uma neoplasia, enquanto outros acreditam ser uma condição pré-maligna por sua associação a tumores malignos (frequentemente adenocarcinoma). ${ }^{4,5}$ A ausência de atipia celular, de mucina entremeada por células epiteliais ${ }^{3,5}$ e de invasão do músculo detrusor da bexiga descarta tumor maligno. ${ }^{2,3,5}$

No caso descrito, trata-se de cistite glandular do tipo intestinal, florida. Macroscopicamente, apresentou-se como lesão bolhosa, de limites imprecisos; microscopicamente, apresentava epitélio colunar, com produção de mucina, mas não possuía atipia celular, mucina entremeada com células epiteliais ou invasão do detrusor da bexiga, o que descartava qualquer hipótese de malignidade.

A maioria dos casos de cistite glandular é assintomática, sendo que os pacientes sintomáticos, normalmente, apresentam hematúria, sintomas urinários irritativos e típicos de cistite crônica. ${ }^{2}$ Em nosso caso, o paciente apresentava sintomas irritativos e obstrutivos, mas não hematúria e cistite crônica.

O diagnóstico diferencial é feito com relação a adenocarcinoma e adenoma nefrogênico. Este é altamente incidente em bexigas manipuladas ou traumatizadas 
e, frequentemente, está associado à cistite crônica em adultos. ${ }^{2}$ Há controvérsias sobre o tratamento precoce agressivo: vários estudos propõem a ressecção transuretral e o acompanhamento cistoscópico, com realização de biópsias seriadas até que ocorra a degeneração para adenocarcinoma; outros advogam o tratamento agressivo de início. ${ }^{2}$

A história natural da cistite glandular após a ressecção transuretral é pouco conhecida. Muitos pacientes não necessitam de cirurgia mais agressiva posteriormente, mas é desconhecida a proporção de pacientes que voltam a apresentar sintomas ou persistência da hematúria. A obstrução ureteral é uma rara complicação dessa doença e resulta da infiltração da submucosa periureteral. ${ }^{1}$

No caso descrito, a tomografia computadorizada demonstrou obstrução ureteral bilateralmente. A cirurgia mais extensa tem sido proposta para casos de sintomatologia persistente ou severa e acometimento ureteral. A forma intestinal florida é considerada como a mais rara forma de apresentação e a mais incapacitante e, geralmente, requer ressecção profunda da lesão. ${ }^{2}$

A cistectomia radical, utilizando-se da construção de neobexiga, tem recebido pouca atenção nos estudos publicados. Entretanto, poucas são as opções de tratamento para casos graves, como reimplante ureteral na cúpula vesical e repetidas ressecções endoscópicas. Tratamentos alternativos, como injeção intravesical de corticoide ou tratamento com laser têm sido descritos. ${ }^{8,9,10}$

\section{REFERÊNCIAS}

1. Black PC, Lange PH. Cystoprostatectomy and neobladder construction for florid cystitis glandularis. Urology 2005; 65:174 e16-7.

2. Kaya C, Akpinar IN, Aker F, Turkeri LN. Large cystitis glandularis: a very rare cause of severe obstructive urinary symptoms in an adult. Int Urol Nephrol 2007; 39:441-4.

3. Weiss MA. Bladder lesion in a 59-year-old man. Contemp Urol 2007; 31-3.

4. Mitre AI, Silveira CAP, Leite KRM, Piovesan AC. Glandular cystitis - a rare benign condition presenting as a pseudo-tumor of the bladder. Clinics 2007; 62:93-4.

5. Troyas RG, Calvo JJ, Romero BR, Dorronsoro MLG. Cistitis glandular florida de tipo intestinal con extravasación de mucina: una lesión que simula un tumor. Actas Urol Esp 2003; 27:297-300.

6. Bullock PS, Thoni DE, Murph WM. The significance of colonic mucosa (intestinal metaplasia) involving the urinary tract. Cancer 1987; 59:2086-90.

7. Davis G, Castro JE. Cystitis glandularis. Urology 1977 ; 10:128-9.

8. Holder P, Plail R, Witherow R et al. Cystitis glandularis reversal with intravesical steroid therapy. $\mathrm{Br} \mathrm{J}$ Urol 1990; 65:547-8.

9. Stillwell T, Patterson D, Farrow G et al. Neodymium: YAG laser treatment of cystitis glandularis. J Urol 1988; 139:1298-9.

10. Granados EA, Algaba F, Vicente Rodriguez J. Cystitis glandularis. Arch Esp Urol 1999; 52:119-22. 